\title{
Empathy, mirror neurons and SYNC
}

\author{
Ryszard Praszkier
}

Received: 5 March 2014/ Accepted: 25 November 2014/Published online: 14 December 2014

(C) The Author(s) 2014. This article is published with open access at Springerlink.com

\begin{abstract}
This article explains how people synchronize their thoughts through empathetic relationships and points out the elementary neuronal mechanisms orchestrating this process. The many dimensions of empathy are discussed, as is the manner by which empathy affects health and disorders. A case study of teaching children empathy, with positive results, is presented. Mirror neurons, the recently discovered mechanism underlying empathy, are characterized, followed by a theory of brain-to-brain coupling. This neuro-tuning, seen as a kind of synchronization (SYNC) between brains and between individuals, takes various forms, including frequency aspects of language use and the understanding that develops regardless of the difference in spoken tongues. Going beyond individualto-individual empathy and SYNC, the article explores the phenomenon of synchronization in groups and points out how synchronization increases group cooperation and performance.
\end{abstract}

Keywords Empathy · Mirror neurons - Synchronization - Social SYNC · Embodied simulation · Neuro-synchronization

\section{Introduction}

We sometimes feel as if we just resonate with something or someone, and this feeling seems far beyond mere intellectual cognition. It happens in various situations, for example while watching a movie or connecting with people or groups. What is the mechanism of this "resonance"?

Let's take the example of watching and feeling a film, as movies can affect us deeply, far more than we might realize at the time. It's intriguing to pry open the 
filmmaker's workshop and take a closer look at the methods used to influence the spectators. Let's uncover this magic, using Dr. Karen Pearlman's book Cutting Rhythms: Shaping the Film Edit (Pearlman 2009). The author, well known for her pioneering work in articulating the underlying principles of rhythm in film is, says:

Rhythm shapes cycles of tension and release by shaping time, energy, and movement through the film in patterns designed to provoke and modulate particular qualities of empathetic response. I emphasize empathetic here, because rhythm is a felt phenomenon; the spectators' experience of rhythm [-] is an embodied, physiological, temporal, and energetic participation in the movement of images, emotions, and events in the film. (p. 62-63)

The author refers then to rhythms that evoke empathetic responses. This is done by creating cycles of tension and release, synchronizing the spectator's rhythms to the film's pulse and its fluctuations. Synchronization (SYNC) is perceived as pivotal for shaping the film's rhythms into a vehicle that triggers an empathetic resonance.

Taking a closer look, Pearlman mentions physiology and neuroscience: The mirror neurons embedded in our brain reflect the movement and sounds seen on the screen and beef up the spectator's empathy. More than that, a body-based, empathykindling path (called kinesthetic empathy) induces an inner image of movements seen onscreen. The observer essentially "internally simulates" the observed movements and, without actually moving, feels his own body configuration change in response.

Both those paths (mirror neurons and kinesthetic interaction) make us experience physiological tension and release virtually simultaneously, as we perceive the movie's patterns of intensity and relaxation; and thus we enter the universe of synchronization. According to Pearlman, by modulating tension and release, rhythm acts on the observer as a generative aspect of his or her comprehension of a film, regardless of its genre, topic or quality.

The role of the editor is to determine the timing, pacing, and trajectory phrasing of its movement, and spectators' bodies respond to this rhythm [-] and SYNC up into a physiological phenomenon of feeling with (Pearlman ibid, p. 68).

The film editor's insights are supported by the conclusions of various researchers. For example, Gallese and Guerra (2013), as a result of discoveries in neuroscience, propose a novel approach to cinema that considers cognition but also incorporates the body expression. The triad: film, body and brain, can be a new basis for understanding film theory. With the advancement of new digital technologies for analyzing movies and individuals' reactions to them (Shimamura 2013a), there opens a new approach in cognitive neuroscience, the embodiment of which is applied to film studies (Gallese and Guerra 2012). New disciplines are emerging: Neuroaesthetics (Chatterje 2012; Kirk 2012) and Psychocinematics (Shimamura 2013b).

It seems worthwhile to take a closer look at our film editor's conclusions, reached through professional experience and intuition. Are her conjectures supported in research outside the realm of cinema? If so, does that mean that this influencing- 
through-rhythm mechanism works outside the movie-watching experience? And finally, captivating notion: Maybe this isn't an isolated phenomenon. Maybe people also communicate through rhythm in everyday life?

The departure point for addressing these questions will be the notion of empathy. Next we will document the neuroscience behind this phenomenon, and finally, we'll look at the synchronization processes based on mirror neurons and empathy.

\section{Being in the shoes of others}

\subsection{Empathy}

Neither animals nor humans are selfish, writes a known primatologist De Waal (2009). Empathy is an ancient trait, as old as maternal care; mothering based on being sensitive to and anticipating the needs of developing offspring is more successful than less responsive types of care.

De Waal thus turns upside down the long-held notion of humans (and other animals) as competitive and supremely selfish, concerned only with their own survival and perhaps the survival of their offspring. Instead the author finds huge amounts of empathy, cooperation, and concern amongst species, tribes and other groups, and families.

It all starts with "emotional contagion," which is a primitive form of true empathy. In essence, we are simply infected with others' emotions or behavior. De Wald holds that cognitive empathy is a higher state that allows us to understand and actually feel the emotions of the others.

This capacity arose long ago with motor mimicry and emotional contagion, after which, evolution brought small modifications, until our ancestors not only felt what others felt but also understood what others might want or need. This enhanced their ability to survive and propagate.

\subsubsection{When empathy was discovered?}

Prior to the development of the notion of empathy, Theodor Lipps ${ }^{1}$ introduced the term Einfühlung or Einfühlungsvermögen (German: "feeling with" or "managing feeling with"), which referred to the tendency of perceivers to project themselves into the objects of perception and experience them as being "in" the object, so that they were "felt" as well as "seen" (Håkansson 2003). The term empathy per se was coined by Edward Bradford Titchener, ${ }^{2}$ in the process of developing Lipp's concept of Einfühlungsvermögen (Håkansson 2003).

\footnotetext{
${ }^{1}$ German philosopher, nineteenth/twentieth century, 1851-1914.

2 British psychologist known for his studies of the structure of mind, 1867-1927.
} 


\subsubsection{Empathy seen as an affective reaction}

It seems that most definitions highlight the affective reaction as the backbone of empathy. This approach is well represented by Roy (2010), who posits that empathy is an essential part of emotions and is itself a specific emotion involving a feeling element of familiarity or connection and a bodily reaction of verbal or nonverbal communication. Empathy in general would mean feeling what the other person is feeling and "being in the shoes of the other."

Eisenberg and Strayer (1990): "In our view, empathy involves sharing the perceived emotion of another- "feeling with" another" (p 5) or Roy (2010): "Empathy is an essential part of emotions and is itself a specific emotion involving a feeling element of familiarity or connection and a bodily reaction of verbal or nonverbal communication. Empathy in general would mean feeling what the other person is feeling and "being in the shoes of the other." [-] Empathy is closely related to intuition and, like intuition, helps in the understanding and recognition of emotions in others. Empathy is thus described as recognizing other people's emotions through intuition and is marked by a feeling of connecting to the other person."

Stotland (1969), Hoffman (1987), and Barnett et al. (1987) also delineated empathy in affective terms and conceptualized empathy as feeling a vicarious emotion that is congruent with, but not necessarily identical to, the emotion of another.

\subsubsection{Cognitive and epistemological aspects of empathy}

In the 1930s both Mead $^{3}$ (1967) and Piaget ${ }^{4}$ (2008) emphasized the cognitive aspects of empathy, highlighting the ability to understand the other, beyond mere "feeling into." Mead, especially, saw children's ability to role play as the key to their development. He put forward that meaning "arises in experience through the individual stimulating himself to take the attitude of the other in his reaction toward the object" (Mead ibid, p. 545). Piaget emphasized empathy as a cognitive function requiring an individual to de-focus on her or himself and imagine the role of another (Håkansson 2003).

Bandura $(1969,1971)$ introduced the mechanism of vicarious learning, i.e., an ability to emotionally learn by observation; he noticed that the two components of vicarious learning are firstly, the behavior of a model that produces reinforcement for a particular behavior, and secondly, positive emotional reactions aroused in the observer.

De Vignemont and Singer (2006) also highlight the epistemological role of empathy, because by sharing the emotional state of others, we are well-equipped to develop a more precise and direct estimate of others' plausible future actions. Also empathy provides knowledge about important environmental properties, as we emotionally learn by observation, e.g., seeing someone being burned by a machine,

\footnotetext{
3 American philosopher, sociologist and psychologist, 1863-1931.

${ }^{4}$ Swiss (French-speaking) psychologist known for his developmental studies with children, 1896-1980.
} 
we attach a negative "avoidance" value to the machine, without having experienced pain ourselves. In this sense empathy is an efficient computation tool for acquiring knowledge about the attributes of the world around us.

\subsubsection{Empathy as connectedness}

Empathy relates to connectedness and to a sense of just knowing what another person is feeling, and is closely related to intuition (Roy 2010). Moreover, it can be defined as recognizing other people's emotions through intuition and a feeling of connecting to the other person (Roy idem). Pavlovich and Krahnke (2012) document that empathy enhances connectedness through the unconscious sharing of neuropathways that dissolve the barriers between self and other.

Gallese $(2005,2009)$ analyzes connectedness as embodied simulation. In his recent paper (Gallese 2014) he highlights the role of the bodily interaction indicating that the discovery of mirror neurons led to the proposal of an embodied approach to intersubjectivity; in that perspective intersubjectivity is being viewed as intercorporeality.

\subsubsection{Empathy as a mixed affective and cognitive reaction}

Eisenberg (2002) considered both emotional and cognitive factors and defined empathy as "an affective response that stems from the apprehension or comprehension of another's emotional state or condition, and that is similar to what the other person is feeling or would be expected to feel" (p 135). Similarly, Davis (1996), Pavlovich and Krahnke (2012), and Ickes (1997) depict the emotional and cognitive aspects of empathy.

\subsubsection{Moral aspects of empathy}

Empathy plays a key role in contribution to altruism and compassion for others in physical, psychological, or economic distress. It provides feelings of guilt over harming someone and feelings of anger at others who do harm. Empathy is a pivotal factor in the parental behaviors that foster moral internalization in children. It is also a gateway to internalizing abstract moral principles (Hoffman 2001), especially in that it includes "ethical responsibility in the face of the Other" (Thompson 2001, p. 17).

\subsubsection{Social aspects of empathy}

Empathy is also a departure point for pro-social behavior and cooperation. People help others more when they report having empathized with them. On the contrary, individuals with empathy deficits are more likely to display aggressive, antisocial behavior toward others. Some say that lack of empathy during development results in lack of morality. However, empathy is not a necessary condition for taking prosocial action; it additionally requires sympathy to be a motivation for reaching out and helping (De Vignemont and Singer 2006). 


\subsubsection{Kinesthetic empathy interaction (KEI)}

Sometimes strange things happen to one's imagination, especially when one watches a dance performance. Spectators of dance, even while seated, often feel they are participating in the movements they observe and experience related feelings and ideas. This is called kinesthetic empathy interaction (KEI), delineated as movement empathy, a foundational technique of dance/movement therapy, in which practitioner and client move in synchrony. The other name used for this phenomenon is attunement. Spectators can internally simulate movement sensations of speed, effort, and changing body configuration (Hagendoorn 2004; Fogtmann 2007).

However, some call this this bodily reaction "motor mimicry" and depict it as "primitive empathy," see: Eisenberg and Strayer (1990).

\subsubsection{The complex phenomenon of empathy}

Empathy seems a complex phenomenon, having many dimensions: interactive, cognitive, affective, epistemological, moral, social, and collaborative—see Fig. 1:

This leads us to a syndromic concept of empathy, seen as the ability, constructed by emotional, cognitive, behavioral and communicational competencies, to tune into the internal states of the others.

\subsubsection{Defining empathy}

Some authors propose that there are three primary aspects of empathy: an affective response to another person, a cognitive capacity to take the perspective of the other person, and some self-regulatory and monitoring mechanisms that modulate inner states evoked by the empathetic reaction (Thompson 2001). However, the variety of definitions of empathy have been vague or confusing; as a result, operational

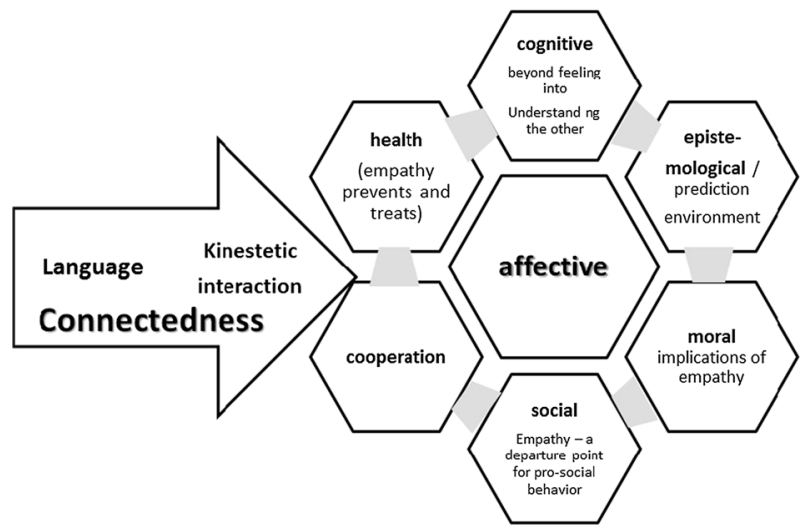

Fig. 1 The phenomenon of empathy 
definitions of and measurement techniques for empathy vary greatly from one study to another (Gerdes et al. 2010, 2011; Segal et al. 2012).

Empathy so defined could manifest itself regardless of the reaction of the other, including in those situations where the other doesn't even observe our reaction. In other words: A person may express empathy more intensively with some people than with others, e.g., some may empathize especially strongly with children of alcohol abusers or with social innovators struggling against all odds. The level of a person's empathetic reaction may also vary according to the situation, e.g., some may be more prone to empathize in the context of natural disasters, others in the context of a performing art. Empathy might lead to action ("empathetic action", Gerdes et al. 2011) but not necessarily (Hoffman 2001); it is, however, usually associated with intention to respond compassionately to another person's distress (Thompson 2001).

Empathy differs from compassion as compassion demonstrates caring for others, but it tends to be limited to feeling sorry for. It also differs from sympathy defined as "feeling an emotion triggered by seeing/learning of someone else's distress which moves you to want to alleviate their suffering." (Baron-Cohen and Wheelwright 2004, p. 165). Empathy goes further, being an ability to see the world through others' eyes, sensing and understanding their feelings in the same way as they do (Segal 2007).

\subsubsection{Measuring empathy}

The conceptualization of empathy, especially the embraced dimensions (cognitive, emotional, behavioral, etc.), determines the measurement techniques, which differ in various studies, making it difficult to identify one, comprehensive approach (Gerdes et al. 2010).

Currently, one of the two most popular assessments, the Empathy Quotient (EQ), designed to be short and easy to use, encompasses both affective and cognitive components (Baron-Cohen and Wheelwright 2004). Satisfactorily valid and reliable it is especially applicable to the field of mental health, i.e., to the Autism Spectrum Disorder (Lawrence et al. 2004).

The other approach developed in the social work field is called Empathy Assessment Index (EAI). It's based on five dimensions: affective response, selfother awareness, perspective taking, emotion regulation, and empathic attitudes (Lietz et al. 2011; Gerdes et al. 2011) and as such, seems comprehensive, grasping all the critical components of empathy.

What's missing, however, is the kinesthetic interaction, a critical component for measuring SYNC (see later in this article).

\subsection{Can we learn empathy?}

We can definitely ingrain and enhance this capacity in small children. De Wall also (ibid) believes that empathy can be enhanced, as we do when we urge a child who is hogging all the toys to be more considerate of her playmates. 


\subsubsection{Roots of Empathy}

Some are doing that work now. For example, Mary Gordon (2005) is known for her program Roots of Empathy, which significantly reduces aggression among schoolchildren while raising social/emotional competence and increasing empathy. In the program a parent and infant engage with students in the classroom. A Roots of Empathy Instructor guides the children as they observe the relationship between baby and parent, helping them understand the baby's intentions and emotions. Through this model of experiential learning, the baby serves as "teacher" and catalyst, helping children identify and reflect on their own feelings and the feelings of others. An longitudinal research on the impact of the Roots of Empathy program (Berkowitz and Bier 2007) documented that Roots of Empathy children demonstrated lasting:

- increase in social and emotional knowledge

- decrease in aggression

- increase in pro-social behavior (e.g., sharing, helping, and including)

- increase in perceptions among ROE students of the classroom as a caring environment

- increased understanding of infants and parenting.

\subsubsection{Immerse virtual reality embodiment reducing racial bias}

Although the act of merely observing in immerse virtual reality (IVR) the pain of other racial group representatives doesn't stimulate sensorimotor empathic brain responses (measured using transcranial magnetic stimulation; Avenanti et al. 2010), it was noted that embodiment in IVR might reduce racial prejudice. Experiments with the embodiment of light-skinned participants in a dark-skinned virtual body (VB) significantly reduced participants' implicit racial bias against dark-skinned people (Peck et al. 2013; Groom et al. 2009). Notably, however, other techniques, such as imagining the dark-skinned person's perspective in real life, had no significant impact on racial bias (Groom et al. ibid).

This means that IVR-embodiment into another's VB may reduce racial (or political, interpersonal, and other) biases and merits further exploration in areas such as conflict resolution and peacemaking.

\subsection{Empathy helps}

The Roots of Empathy program indicates that developing empathy as a means to prevent antisocial behaviors such as bullying and juvenile aggression also helps prevent later problems including dropouts, juvenile delinquency, and addiction.

On a societal level, the ability to share other people's emotional experiences and to react to them might facilitate social communication and create social coherence (De Vignemont and Singer idem). 


\subsubsection{Empathy prevents}

Indeed, empathy is identified as an essential ingredient for effective parenting, especially for the mother of a distressed infant, and as protection against the possibility of aggression (Dolan and Fullam 2007). Engaging empathic processes in children and adolescents results in reducing their aggression; this sort of empathy training may be useful for encouraging positive social behaviors (Björkqvist 2007). It also builds social intelligence and negatively correlates with direct types of aggression: physical and verbal (Kaukiainen et al. 1999). Moreover, there are better prospects for improved long-term prognosis of psychopathy if treatment is aimed at increasing the empathic reaction of children with psychopathic tendencies (James and Blair 2007).

\subsubsection{Healing by empathy}

There are also indications that empathy may be a curative factor in various disorders (Farrow et al. 2005); the authors proved that building empathy is useful for healing PTSD. Scanning the brain (fMRI) they found that PTSD patients, after a cycle of modified cognitive behavioral therapy aimed at understanding others and being more empathetic, demonstrate a significant increase in the neural response to social cognition tasks. These findings can be a gateway to an empathy-based therapy program for PTSD patients.

And who hasn't experienced the beneficial influence of benevolent medical care? Researchers also document the vital importance of the doctor-patient relationship and the role of empathy. Doctors should listen to their patients, communicate with them, and thus the physician and patient become partners in the healing process. This enables the process of healing by empathy (Adams 2010). Moreover, empathy is an important element of healthcare professional and patient communication and is a key feature of emotional intelligence. Health professionals should be trained to effectively implement empathy, in order to achieve the desired therapeutic results (Ioannidou and Konstantikaki 2008).

A very special healing relationship based on empathy is the psychotherapeutic bond. Since the advent of Carl Rogers' client-centered approach based on empathetic understanding (Rogers 2003), the results of much research indicate that empathy, in its contemporary understanding, is not only an essential part of the therapeutic alliance (Bergemann 2011), but also (or first and foremost) a curative factor per se (Staemmler 2011). Truly empathic therapists are also skilled inquirers, sensitively attuned to their clients and appropriately involved in the therapeutic process (Erskine et al. 1999). The quality of the therapeutic relationship is seen as the best predictor of success in psychotherapy and is the backbone of empathetic facilitation of the client's own problem-solving capacities (Bohart and Greenberg 1997).

Immersing oneself in the experience of the other through an empathetic relationship enables sensitive interpretations that help clients access unconscious experience. Moreover, it becomes a gateway to co-constructing new understanding (Bohart ibid). 
A closer look at the psychotherapeutic relationship from the synchrony perspective is presented in this paper.

\section{Empathy neurons}

In the early 1990s, Italian researcher Vittorio Gallese, part of Prof. Giacomo Rizzolatti's group from the University of Parma, made a remarkable and quite unexpected discovery. One day, Gallese was working in a room with a macaque monkey with electrodes implanted in its brain. As Gallese reached for his food, he noticed neurons begin to fire in the monkey's premotor cortex-the same area that showed activity when the animal made a similar gesture (Iacoboni 2009; Society for Neuroscience 2008). How could this happen, when the monkey was sitting still and merely watching him?

This opened the gateway to the discovery of mirror neurons, which revolutionized psychology, providing a unifying framework and helping explain a host of mental abilities that have, hitherto, remained mysterious (Ramachandran 2000). Mirror neurons provide, for the first time in history, a plausible neuropsychological explanation for complex forms of social cognition and interaction (Iacoboni 2009). Some use vivid names such as "empathy neurons" or "Dalai Lama neurons," to describe mirror neurons, holding that they dissolve the barrier between self and others (Ramachandran 2006). Neuroscience has begun to understand the mechanisms of visual processing that allow our brain to build a representation of what it sees in the world (Keysers 2011).

\subsection{Mirror neurons}

The Parma experiments were confirmed in many other settings, e.g., researchers at UCLA found that cells in the human anterior cingulate, which normally fire when you poke the patient with a needle ("pain neurons"), will also fire when the patient watches another patient being poked (Ramachandran 2006). Other studies using different experimental methodologies and techniques have demonstrated in the human brain the existence of a mechanism directly mapping action perception and execution, defined as the Mirror Neuron System, MNS (Gallese 2003, 2009). It appeared that during mere action observation there is a strong activation of premotor and posterior parietal areas: the same regions that are activated when we move, are also activated when we observe the same motor acts executed by others. The MNS in humans is not only involved in imitation of simple movements, but also in imitation learning of complex skills, in the perception of communicative actions, and in the detection of action intentions (Gallese 2009). Similarly, it was shown that mirror neurons are involved in our capacity to share emotions and sensations with others (Gallese 2003, 2006, 2009; De Vignemont and Singer 2006).

Various findings suggest that multiple systems in the human's brain may be endowed with neural mechanisms of mirroring for both the integration and differentiation of perceptual and motor aspects of actions performed by self and others (Mukamel et al. 2010; Keyserss and Gazzola 2010). 
Moreover, mirror neurons are involved in human communication, amplifying cognition of the speech of others and enhancing the ability to communicate in an unknown language (Hasson et al. 2012; Stephens et al. 2010). This MN mechanism also enables the observer to understand the intention behind an observed motor act, in addition to the goal of it (Rizzolatti and Fabbri-Destro 2008).

Recapping, mirror neurons underlie the empathizing processes-triggering the same brain activation patterns when subjects observe emotions in others as when they feel their own emotions. This explains how we feel the emotions of others as if they were our own (De Vignemont and Singer 2006).

\subsection{Embodied simulation}

According to this perspective, to perceive an action is equivalent to internally simulating it. This implicit, automatic, and unconscious process of embodied simulation enables the observer to use his/her own resources to penetrate the world of the other without explicitly theorizing about it. A process of implicit, prereflexive action simulation automatically establishes a direct implicit link between the other and the observer (Gallese 2003). ${ }^{5}$

The discovery of mirror neurons, responding both to action execution and observation, suggested an embodied approach to mental simulation. Embodied simulation is understood as a basic functional mechanism by which our brain/body system models its contact with the world; it constitutes a crucial functioning mechanism in social cognition. Embodied simulation becomes a common underlying functional mechanism that enables one to feel the actions, intentions, feelings, and emotions of others, thus grounding our identification with and connectedness to others (Gallese 2008, 2009, 2011; Gallese and Sinigaglia 2011).

We are implicitly aware of the encountered other's similarity to us because we literally embody it. The very same neural base activated when our own actions are executed or emotions and sensations are subjectively experienced, is also activated when the same actions, emotions, and sensations are executed or experienced by others.

Metaphorically speaking, through brain mirroring, "the other" becomes "self", as her or his action is represented in our MNS system just as if we had taken the same action. The sharp distinction, classically drawn between "I" and "she" or "he" at the level of acting and experiencing emotions, appears to be much more blurred at the level of the neural mechanisms mapping it. The gap between the two perspectives is bridged by the way intentional relations are functionally mapped at the neural-body level (Gallese 2011).

\subsection{Mirror neurons dysfunctions}

Dysfunctional simulation mechanisms may underlie the social and communicative deficits seen in individuals with autism spectrum disorders (ASD), which are largely characterized by deficits in imitation, pragmatic language, theory of mind, and

\footnotetext{
$\overline{5}$ Would be interesting to explore if this is similar to the so called "vibration" between people.
} 
empathy (Williams et al. 2001; Oberman and Ramachandran 2007; Oberman et al. 2005; Gallese 2003, 2006; Iacoboni and Dapretto 2006; Oberman and Ramachandran 2007).

The theory of mind was used to delineate a cognitive deficit underlying social impairment in childhood autism. It was documented that autistic children lack such a 'theory,' the implication of which would be that they would be unable to impute beliefs to others and to predict their behavior (Baron-Cohen et al. 1985; Frith and Happé 1994; Tager-Flusberg 2007). Compared to control groups they alone failed to attribute beliefs to others, ${ }^{6}$ indicating that the dysfunction is independent of mental retardation and is specific to autism (Baron-Cohen et al. ibid). Findings suggest that most significant deficits of ASD children (as compared with mainstream representatives) is in performing tasks based on the theory of mind (Hamilton et al. 2007).

Along with the development of the neuroscience of MN came a common conviction that internal simulation mechanisms, such as the mirror neuron system, are necessary for normal development of recognition, imitation, empathy, and language, and especially - the theory of mind (Meltzoff 2011). It became evident that mirror neurons are performing precisely the same functions that are disrupted in autism (Gallese et al. 2004; Ramachandran and Oberman 2006; Ferrari and Rizzolatti 2014).

Research on motor functioning in ASD indicates that impairments to reaching and grasping emerge early in life and affect the planning and execution of motor programs (Sacrey et al. 2014). The functional properties of the mirror neuron system indicate that action understanding may be primarily based on the pivotal role of motor cognition that underpins one's own capacity to act (Gallese et al. 2009; Rizzolatti and Fogassi 2014).

Autistic children also experience severe problems with their facial expressions of emotions and their understanding of the expressions of others. They do not show automatic mimicry of the facial expression of basic emotions, as revealed by the study of muscle electrical activity, shown in electromyography (EMG recordings). This explains the lack of empathic engagement displayed by autistic children and seems to stem from defective embodied simulation, likely regulated by the MNS (Gallese 2009).

Moreover, the autistic child's observation of motor acts using the leg, hand and mouth usually activates relevant parts of the inferior frontal gyrus (IFG). However, the fMRI study revealed that there is also a significantly weaker activation in the IFG in children with autism as compared to typically developing children (Rizzolatti and Fabbri-Destro 2010).

Other disorders were also found to be linked to the dysfunctions of MNS: the vulnerability of schizophrenia (Gallese 2003), depression (O'Connor et al. 2007), as well as other symptoms, e.g. echolalia (Williams et al. 2001).

\footnotetext{
${ }^{6}$ E.g., mentally disabled children, though the mental age of the autistic children was higher than that of the control groups.
} 


\subsection{Modifying MNS?}

Analyzing the aforementioned Roots of Empathy program and its longitudinal impact, we see that it's possible to modify the MNS, though presumably not beyond a certain age, up to which the brain maintains its mirror neurons' plasticity. Surpassing this age threshold would then lead to gradual freezing of the brain's plasticity, leaving us with the form of mirror neurons made by that time. This age brink has yet to be studied and identified; An analysis of Mary Gordon's Roots of Empathy program indicates that it falls somewhere between Kindergarten and third grade, though this conjecture needs to be verified. Further research may also determine what happens after this age milestone is surpassed: would there still be some way to modify the MNS, e.g., in the case of older autistic children?

\section{Empathy and SYNC}

\subsection{Synchronization}

The aforementioned empathy and embodied simulation indicate that something extraordinary happens between people when they communicate, and the lifeblood of this wonder seems to be the mirror neurons, driving the process of intentional attunement (Gallese 2008, 2009, 2011). Two brains attune and couple, synchronizing beyond and regardless of the content of communication.

Synchronization is understood here in a broader sense, as coordination of events to operate a system. ${ }^{7}$ Brown and Kocarev (2000) highlight that SYNC can be considered if the properties of two subsystems (parts of a larger interacting system) agree in time. In the context of brain coupling, SYNC may be defined as coordination of brains to operate in accord and in time. The embodied simulation may lead to a situation where two brains become tuned to each other.

\subsection{Brain-to-brain coupling}

This process is attributed to the emergence of complex behaviors that require the coordination of actions among individuals according to a shared set of rules. The neural processes in one brain are coupled to the neural processes in another brain via the transmission of signals through the environment. Two brains synchronize. This process of brain-to-brain coupling looks exactly like a wireless communication system in which two brains are coupled via the transmission of a physical signal (e.g., sound, pressure or chemical compound) through the shared physical environment (Hasson et al. 2012).

There are numerous joined behaviors such as mating, group cohesion, and predator avoidance, which depend on accurate production and perception of social signals. Development processes ultimately must result in coupling between the

\footnotetext{
${ }^{7}$ Synchronization is also defined in a narrow sense, relating to oscillators, e.g., "synchronization is an adjustment of rhythms of oscillating objects due to their weak interaction" (Pikovsky et al. 2003, p. 8).
} 
sensory systems of one individual with the signals produced by the motor system of another individual (Hasson et al. ibid).

\subsubsection{Interactive alignment}

Interactive alignment is the unconscious process that enables communication and dialogue between people. Two interlocutors simultaneously align their representations at different linguistic levels by imitating each other's choices of speech sounds, grammatical forms, words, and meanings. ("I handed John his lunchbox today" will trigger "and I handed him his coat..." instead of "I gave him his coat..."); in the first case both utterances use the same words to the extent possible.

Using the MRI it was documented that, during successful communication, the speaker's and listener's brains exhibit joint, temporally coupled, response patterns (Hasson et al. ibid) synchronizing over time. Moreover, Dumas et al. (2010), when EEG-scanning pairs of subjects imitating each other, discovered that states of interactional synchrony correlate with the emergence of an interbrain synchronizing network. ${ }^{8}$ The authors concluded that interbrain neural synchronizations can be seen as several aspects of the ongoing interactional synchrony, anticipation of other's actions, and co-regulation of turn-taking.

\subsubsection{Language as brain-to-brain coupling transmitter}

Apparently, one of the transmitters of this attunement is language. However, the discovery is that it is not so much the content, words, and grammar that enable brain-to-brain coupling. It is much more the rhythm of communication.

Across all languages and contexts, the speech signal has its own amplitude modulation (increase or decrease in intensity) consisting of a rhythm that ranges between 3 and $8 \mathrm{~Hz}$. This rhythm is roughly the timescale of the speaker's syllables production (three to eight syllables per second).

Watching the speaker's face is the equivalent of turning up the volume by 15 decibels. The mouth movements during speech are tightly coupled with the speech signal's amplitude modulation. Thus, the speaker's mouth oscillations at a rate of 3-8 Hz are captured by listener's visual system and amplified via numerous sensory pathways in the listener's brain (Hasson et al. ibid).

This would indicate that face-to-face relationship enhances the ability of efficient communication - a conjecture that was documented in various experiments, starting with songbirds that learn much more effectively in social context, if the tutor is a live bird, as opposed to a tape-recording (Baptista and Petrinovich 1984).

Another example: In a series of experiments aimed at analyzing how innovative and novel communication systems emerge, pairs of participants were invited to play cooperative games through interconnected computers. The games required players to communicate, but players could not see, hear, or touch each other. The only

\footnotetext{
8 This process was localized in the alpha-mu band between the right centroparietal regions. Interesting to mention that, in the same research, the comparison between synchronized and non-synchronized interactions showed statistical differences in interbrain phase synchronies for all frequency bands analyzed (alpha-mu, beta, and gamma) except for the theta band.
} 
means of contact were devices that allowed for the exchange of visual signals. (The bar was set high, as they could not use standard graphic forms such as letters or numbers.) So, in order to communicate with each other, players had to invent a novel visual communication system. It was shown that, when there was direct interaction between two (or more) players, innovated signs (basic elements of human communication) quickly emerged (Galantucci 2005; Galantucci and Garrod 2011). However, these new signs did not emerge by isolated individuals who played with an offline partner (Garrod et al. 2007).

Brain-to-brain SYNC is also possible through hand gestures and facial expressions. The experiments document that there are two networks in the brain of the individual who is an observer coupled with the movements of the one who is the signaler (regions associated with the mirror neurons and regions associated with theory-of-mind). This supports the idea that these two networks collaborate during the perception.

\subsection{Neuro-synchronization}

Moreover, it was shown, that this neural networks-to-networks collaboration is shaped in a specific, synchronic form: Applying fMRI to record brain activity from both speakers and listeners during natural verbal communication documents that during successful communication, speakers' and listeners' brains exhibited joint, temporally coupled, response patterns. Additionally, more extensive speakerlistener neural couplings result in more successful communication. Interestingly, this coupling disappears when participants fail to communicate (Stephens et al. 2010).

During social interaction, both participants are modifying their own actions in response to the continuously changing actions of the partner. This continuous mutual adaptation results in interactional synchrony, to which both members contribute. The EEG-recording of communication documented phase synchronizations between two brains related to several oscillatory frequency bands in both partners' brains' right centroparietal scalp regions (Dumas et al. 2010).

This neuro-SYNC especially applies to aforementioned kinesthetic empathy interactions, as "mirror neurons sit adjacent to motor neurons" (Stern 2004, p. 79).

\subsection{Neuro-SYNC applications}

Neuro-SYNC is applied in practice several ways; four examples from various fields are now presented:

\subsubsection{SYNC in psychotherapy}

The psychotherapeutic relationship, previously delineated as empathetic, is also seen as synchronous. For example, in a sequence of encounters the patient and the therapist achieve accordant verbal and non-verbal patterns, regardless the psychotherapeutic 'school' (Ramseyer and Tschacher 2008) leading, by the end, to the 
therapist's and the client's evaluations of success or otherwise being similar (Tschacher et al. 1998).

Even though unintentional movement synchronization is often emerging between interacting humans (Lorenz et al. 2014), it is especially worth exploring in the psychotherapeutic relationship. There were studies on the dyadic synchronization, in association with empathy, in the psychotherapeutic setting, using a new empirical approach: Motion Energy Analysis (MEA), a video-based algorithm that quantifies the amount of movement in various areas of communication. Statistical analysis detected synchrony on the global level, irrespective of the specific body parts moving. Moreover, a highly positive relationship between SYNC and the therapeutic bond was documented (Ramseyer and Tschacher et al. ibid). The authors concluded that this may be a promising concept for research on the therapeutic alliance.

Physiological synchronization appears to be realized at an interpersonal level (between therapist and patient), as well as between different phenomenological levels of the interpersonal system: speech qualities and psycho-physiological variables (Schiepek 2009, p. 335).

Synchronization, especially "here and now" SYNC, is tackled (implicitly) in Daniel Stern's (2004) questions about the nature of "nowness" and the ways in which "now" is experienced between two people. By articulating the essence of the present moment-its duration, characteristics, and temporal architecture and what protects and separates it from past and future-Stern is, in fact, delineating the nature of synchronization between people. His "present intersubjectivity perspective" enables better understanding of the subjects' implicit knowledge and consciousness.

In some cases the neuro-synchronization approach is directly applied to the development of therapeutic techniques, for example, in neuro-dance therapy for autistic children (Lusty 2011) or Neuro-linguistic Programming (NLP, Dilts et al. 1980), well-known since 1980s.

\subsubsection{Rhythms asynchrony as a predictor for early diagnosis}

Analysis of rhythms in the child-parent relationship (e.g. Feldman 2003, 2007; Lin 2011) seems a promising tool for early predictions of various disorders and for shaping the adequate therapeutic procedures.

Trevarthen and Daniel (2005) found that asynchronous rhythm in parent-child or caregiver-child early relationship may be a predictor for some disorders such as autism or Rett syndrome; the authors analyzed the activity-withdrawal rhythms comparing monozygotic twin girls at 11 months and found that the arhythmically behaving infants were diagnosed autistic or Rett.

\subsubsection{Robots' interaction based on the mirror neurons synchronization}

Based on the MN theory and the consequential premise of parity between perception and action, androids were constructed to show how the MN system facilitates the interaction between two robots. Central to the interactional-behavior design was the 
synchronization between neuron groups in different structures of the MN system. The robotic simulations showed the potential of the mirror neuron paradigm for designing socially meaningful behaviors (Barakova 2007; Barakova and Lourens 2009).

Social interaction has a wide spectrum of expressions such as synchronous movements, turn taking, gaze sharing, following, imitation, and conversation. Here a simple interaction behavior of following and turn taking was simulated, so that the turn taking was caused by changing synchronous firing of the oscillatory neurons. It appeared that turn taking has emergent properties due to nonlinear oscillations and their interaction (Barakova 2007).

The experiments with robots proved that the synchronization of the mirror neurons function can lead to complex behaviors, enabling learning and sharing, and, finally, to emergent results.

\subsubsection{Neuromarketing}

Neuromarketing extends classical market research techniques with neuroscience and eye tracking technologies. By merging consumers' visual perception, brain sensorimotor, cognitive, and affective responses, neuro-specialists develop insights into the subconscious of consumers and adapt their marketing strategy accordingly (Fisher et al. 2010). ${ }^{9}$

Researchers use technologies such as functional magnetic resonance imaging (fMRI), electroencephalography (EEG), steady state topography (SST), and positron emission tomography (PET) to measure activity in specific regional spectra of the brain response (Lee et al. 2006).

However, applying neuro-SYNC to marketing may be controversial from an ethical point of view: circumventing consumers' awareness and cognition so as to induce desired behaviors would be seen as a manipulative.

\section{Does it work in groups?}

The existing research mostly relates to the empathetic relationships between individuals. However, do we also empathize with groups? Is there something like social empathy?

\subsection{Social empathy}

Empathy was heretofore characterized as an individual, person-to-person phenomenon. Is it justified to also consider empathy on a social level? Some authors do so (e.g., Segal 2007), positing that social empathy builds upon the classic examination of human behavior in the social environment, systems theory, and person-in-

\footnotetext{
9 See for example the Neuromarketing magazine at www.neuromarketingmagazine.com, article in NYT Making Ads That Whisper to the Brain (at http://www.nytimes.com/2010/11/14/business/14stream. html?adxnnl=1\&adxnnlx=1382847579-t/JKRtdIWt8ScjxY53uITw) or Frontline magazine online (http:// www.pbs.org/wgbh/pages/frontline/shows/persuaders/etc/neuro.html).
} 
environment. However, this is seen from a social worker's perspective, i.e., as an ability to understand people by perceiving or experiencing their life situations and, as a result, gaining insight into structural inequalities and disparities (Segal 2011).

The delineation of social empathy that is proposed here focuses not on individuals but on the relationship between them. In other words, it considers the network of bonds, ties and connections between subjects in a group or society and the potential embedded in those relationships. As such, it relates to "feeling into" and understanding the sometimes latent capacities of groups. Some people simply "feel into" groups or societies. They understand, often instinctually, the group's potential, hidden agendas, or unacknowledged tensions, as well as its unspoken dreams and desires. They also feel well the reasons for stagnation-what makes the situation revert to a certain impassable equilibrium. ${ }^{10}$ Studying the work of social entrepreneurs, Praszkier and Nowak (2012) posit that their specific knack (often instinctual and un-verbalized) is to "feel" the groups and societies they are working with. Analyzing this special aptitude the authors introduced and defined the phenomenon of social empathy as:

- Understanding (in many cases instinctively) the various types of potential, sometimes dormant, embedded in groups and/or societies

- Understanding the pains, needs, and frustrations of groups and/or society, as well as their hidden dreams and desires

- Being aware of the latent tendencies, i.e., directions in which groups or societies could potentially go

- Identifying areas in which groups/societies would eagerly cooperate, and where the likelihood of success is relatively high; identifying areas of motivation by responding to some important, though not necessarily visible, needs.

Group facilitators or social entrepreneurs-individuals who bring substantial and durable change - probably use their social empathy in order to release the groups' or societies' potential. They do that without lecturing, preaching, patronizing, or acting as experts. Instead, they simply catalyze the process they feel buzzing under the surface.

\subsection{Social SYNC}

Taking a closer look at the group dynamics, one finds that many group facilitators use some recurrent group rituals, such as dancing (e.g., the students' AIESEC organization routinely uses group dancing as an icebreaker). They assume that these rituals become a backbone of group synchronization, enabling smoother communication and cooperation.

Does synchrony really influence human behavior in groups? If we think, for example, about the many rituals with recurring elements used in group activities, we

\footnotetext{
${ }^{10}$ In the language of complexity theory, one would say that they understand the attractors, i.e., parameters leading the group or society to revert to the same status quo.
} 
may presume that rituals involving synchronous activities produce some kind of positive emotions.

Consequently, the psychological boundaries between the self and the group weaken, and that motivates members to contribute to the collective good. This conjecture was verified in a series of research projects, which documented that acting in synchrony with others can increase cooperation by strengthening social attachment among group members (Wiltermuth and Heath 2009). Moreover, those who are in synchrony with us are not only perceived to be more similar but also evoke more of our compassion and altruistic behavior than asynchronous individuals experiencing the same difficult conditions (Valdesolo and DeSteno 2011). Furthermore, "the positive emotional contagion group members experienced improved cooperation, decreased conflict, and increased perceived task performance." (Barsade 2002, p. 644).

\section{Précis and conclusions}

In the introduction we presented the conjectures of the film editor, Dr. Karen Pearlman, who holds that the rhythm of cycles of tension and release occurring throughout a film provoke and modulate an empathetic response, understood as a felt and embodied phenomenon operating on many levels: physiological, cognitive, and energetic, and leading to internalization and participation in the film's flow of images, emotions, and events.

When we reviewed the literature we found that Dr. Pearlman's beliefs are precisely at the heart of the matter, that is to say:

- Empathy was delineated as a phenomenon going far beyond simple affective reaction, or even "emotional contagiousness;" it is influencing the epistemological as well as cognitive structures responsible both for understanding and predicting the behavior of the others.

- Its epistemological role is to provide information about the future actions of other people and important environmental properties. Its social role is to serve as the origin of the motivation for cooperative and pro-social behavior, as well as to facilitate effective social communication.

- The neural structures responsible for the development of empathy are mirror neurons, which make us "feel" the reasons for and consequence of an observed action of the other, as if we, ourselves, were performing this action.

- An increasing body of evidence shows that, during joint action, people become implicitly coupled at motor, perceptual and cognitive levels.

- Synchronized brains can create new phenomena, including verbal and nonverbal communication systems and interpersonal social institutions that could not have emerged in species that lack brain-to-brain coupling.

Human acumen for empathetic response is multifaceted and includes: 
- Affective (emotional) reaction (German origin is "feeling with")

- Higher level of cognition (understanding others through "feeling into" their emotions)

- Epistemological abilities (precise and direct estimate of others' plausible future actions)

- Environmental orientation (experiencing others' reaction to the environment, e.g., stress arising from encountering dangerous situations)

- Moral guidance (altruism and compassion for others in physical, psychological, or economic distress)

- Social aspects (initiates pro-social behavior and cooperation; especially when accompanied with sympathy)

- Bodily participation (kinesthetic reacting and participating internally in the observed movements)

Empathy developed at a young age prevents future bullying and reduces aggression; empathy training may be useful for encouraging positive social behaviors. It also builds social intelligence.

This process is possible by dint of the mirror neurons, which react to others' reactions as if they were our own. Mirror neurons provide an "embodied simulation" of the observed person's actions, leading to brain-to-brain coupling and synchronizing of communication and social behaviors.

Social empathy is a clue for "feeling into" and understanding the not necessarily visible tendencies, pains and potential of groups and societies. Group synchronization increases identification, cooperation, and cohesiveness. According to Daniel Stern "social mirror theory argues that there cannot be mirrors in the mind if there are not mirrors in the society" (2004, p. 128). The question for further research is whether we are also equipped with a specific social mirror neurons system, enabling us to tune into and coordinate with the group.

We conjecture that there also exists a specific social empathy, which leads to understanding, often instinctually, of a group's or a society's latent potential, hidden agendas or concealed tensions, and its unspoken dreams and desires. If de Waal (ibid) is right in maintaining that the cooperation of species, including humans, derives from the need for survival in groups, and that groups of animals behave in a logical, well organized way, it may be worth exploring whether there exists some kind of psycho-neurological "detector" of the group's behavior.

A few cases of the application of SYNC in diverse fields have been presented.

Finally, the studies on how people synchronize confirm Dr. Pearlman's hypothesis, demonstrating the phenomenon of brain-to-brain coupling and tuning in, both at the verbal level (often regardless of the difference in spoken languages) and the bodily level. People or groups that are in SYNC perform and communicate better.

Acknowledgments Thanks to Mary Gordon for her meaningful inspiration, to David Brée, Ph.D. for challenging the author with good questions, and to Helen Taylor for her editorial contribution. 
Open Access This article is distributed under the terms of the Creative Commons Attribution License which permits any use, distribution, and reproduction in any medium, provided the original author(s) and the source are credited.

\section{References}

Adams FV (2010) Healing through empathy: an expanded edition. CreateSpace, New York

Avenanti A, Sirigu A, Aglioti SM (2010) Racial bias reduces empathic sensorimotor resonance with other-race pain. Curr Biol 20(11):1018-1022

Dilts R, Bandler RW, DeLozier J (1980) Neuro-linguistic programming: volume 1, the study of the structure of subjective experience. Meta Publications, California

Bandura A (1969) Social-learning theory on identificatory processes. In: Goslin DA (ed) Handbook of socialization theory and research. Houghton Mifflin Co, Boston, pp 213-262

Bandura A (1971) Vicarious and self-identification processes. In: Glaser R (ed) The nature of reinforcement. Academic Press, Salt Lake City, pp 228-278

Baptista LF, Petrinovich L (1984) Social interaction, sensitive phases and the song template hypothesis in the white-crowned sparrow. Anim Behav 32(1):172-174

Barakova EI (2007) Social interaction in Robotic agents emulating the mirror neuron function. IWINAC '07 In: Proceedings of the 2nd international work-conference on nature, Part II. Springer, Heidelberg, pp 389-398

Barakova EI, Lourens T (2009) Mirrorneuron framework yields representations for robot interaction. Neurocomputing 72(4-6):895-900

Barnett MA, Tetreault PA, Masbad I (1987) Empathy with a rape victim: the role of similarity of experience. Violence Vict 2:255-262

Baron-Cohen S, Wheelwright S (2004) The empathy quotient: an investigation of adults with asperger syndrome or high functioning autism, and normal sex differences. J Autism Dev Disord 34(2):163-175

Baron-Cohen S, Leslie AM, Frith U (1985) Does the autistic child have a "theory of mind?". Cognition 21(1):37-46

Barsade SG (2002) The ripple effect: emotional contagion and its influence on group behavior. Adm Sci Q 47(4):644-675

Bergemann E (2011) Exploring psychotherapist empathic attunement from a psychoneurobiological perspective: is empathy enhanced by yoga and meditation?. ProQuest LLC, Ann Arbor

Berkowitz MW, Bier MC (2007) What works in character education. J Res Character Educ 5(1):29-48

Björkqvist K (2007) Empathy, social intelligence and aggression in adolescent boys and girls. In: Farrow TFD, Woodruff PWR (eds) Empathy in mental illness. Cambridge University Press, New York, pp 76-88

Bohart AC, Greenberg LS (1997) Empathy and psychotherapy: an introductory overview. In: Bohart AC, Greenberg LS (eds) empathy reconsidered: new directions in psychotherapy. American Psychological Association, Washington, DC, pp 3-31

Brown R, Kocarev L (2000) A unifying definition of synchronization for dynamical systems. Chaos 10(2):344-349

Chatterje A (2012) Neuroesthetics: Growing Pain of a New Discipline. In: Shimamura AP, Palmer SE (eds) Aesthetic science: connecting minds, brains, and experience. Oxford University Press, New York, pp 299-317

Davis MH (1996) Empathy: a social psychological approach. Westview Press, Boulder

De Vignemont F, Singer T (2006) The empathic brain: how, when and why? Trends Cogn Sci 10(10):435-441

De Waal F (2009) The age of empathy: nature's lessons for a kinder society. Three Rivers Press, New York

Dolan M, Fullam R (2007) Empathy, antisocial behaviour and personality pathology. In: Farrow TFD, Woodruff PWR (eds) Empathy in mental illness. Cambridge University Press, New York, pp 33-48 
Dumas G, Nadel J, Soussignan R, Martinerie J Garnero L (2010) Inter-brain synchronization during social interaction. PLoS One 5(8):e12166. doi:10.1371/journal.pone.0012166. http://www.plosone.org/ article/info:doi/10.1371/journal.pone.0012166. Accessed 26 Nov 2014

Eisenberg N (2002) Empathy-related emotional responses, altruism, and their socialization. In: Davidson RJ, Harrington A (eds) Visions of compassion: western scientists and Tibetan Buddhists examine human nature. Oxford University Press, New York, pp 131-164

Eisenberg N, Strayer J (1990) Critical issues in the study of empathy. In: Eisenberg N, Strayer J (eds) Empathy and its development. Cambridge University Press, Cambridge, pp 3-13

Erskine R, Moursund J, Trautmann R (1999) Beyond empathy: a therapy of contact-in-relationship. Routledge, New York

Farrow T, Hunter M, Wilkinson I, Gouneea C, Fawbert D, Smith R, Lee K, Mason S, Spence S, Woodruff $P$ (2005) Quantifiable change in functional brain response to empathic and forgivability judgments with resolution of posttraumatic stress disorder. Psychiatry Res Neuroimaging 140(1):45-53

Feldman R (2003) Infant-mother and infant-father synchrony: the coregulation of positive arousal. Inf Mental Health J 24(1):1-23

Feldman R (2007) Parent-infant synchrony and the construction of shared timing; physiological precursors, developmental outcomes, and risk conditions. J Child Psychol Psychiatry 48(3-4):329-354

Ferrari PF, Rizzolatti G (2014) Mirror neuron research: the past and the future. Philos T R Soc B. doi:10. 1098/rstb.2013.0169

Fisher CE, Chin L, Klitzman R (2010) Defining neuromarketing: practices and professional challenges. Harv Rev Psychiatry 18(4):230-237

Fogtmann MH (2007) Kinesthetic empathy interaction-exploring the possibilities of psychomotor abilities in interaction design. In: Proceedings of the second international workshop on physicality, UWIC Press, pp 37-41

Frith U, Happé F (1994) Autism: beyond "theory of mind". Cognition 40(1-3):115-132

Galantucci B (2005) An experimental study of the emergence of human communication systems. Cogn Sci 29(5):737-767

Galantucci B, Garrod S (2011) Experimental semiotics: a review. Front Hum Neurosci 5(11). doi:10. 3389/fnhum.2011.00011. www.ncbi.nlm.nih.gov/pmc/articles/PMC3043271. Accessed 26 Nov 2014

Gallese V (2003) The Roots of Empathy: the shared manifold hypothesis and the neural basis of intersubjectivity. Psychopathology 36(4):171-180

Gallese V (2005) Embodied simulation: from neurons to phenomenal experience. Phenomenol Cogn Sci 4(1):23-48

Gallese V (2006) Intentional attunement: a neurophysiological perspective on social cognition and its disruption in autism. Brain Res 1079(1):15-24

Gallese V (2008) Empathy, embodied simulation, and the brain: commentary on Aragno and Zepf/ Hartmann. J Am Psychoanal Assess 56(3):769-781

Gallese V (2009) Mirror neurons, embodied simulation, and the neural basis of social identification. Psychoanal Dialogues 19(5):519-536

Gallese V (2011) Mirror neurons and art. In: Bacci F, Melcher D (eds) Art and the senses. Oxford University Press, New York, pp 445-463

Gallese V (2014) Bodily selves in relation: embodied simulation as second-person perspective on intersubjectivity. Philos T R Soc B 369(1644):20130177

Gallese V, Guerra M (2012) Embodying movies: embodied simulation and film studies. Cine J Philos Mov Image 3:183-210

Gallese V, Guerra M (2013) Film, corpo, cervello: prospettive naturalistiche per la teoria del film. Fata Morgana 20:77-91

Gallese V, Sinigaglia C (2011) What is so special about embodied simulation? Trends Cogn Sci 15(11):512-519

Gallese V, Keysers Ch, Rizzolatt C (2004) A unifying view of the basis of social cognition. Trends Cogn Sci 8(9):396-403

Gallese V, Rochat M, Cossu G, Sinigaglia C (2009) Motor cognition and its role in the phylogeny and ontogeny of action understanding. Dev Psychol 45(1):103-113

Garrod S, Fay N, Lee J, Oberlander J, MacLeod T (2007) Foundations of representation: where might graphical symbol systems come from? Cogn Sci 31(6):961-987 
Gerdes KE, Segal EA, Lietz CA (2010) Conceptualizing and measuring empathy. Br J Soc Work 40(7):2326-2343

Gerdes KE, Lietz CA, Segal EA (2011) Measuring empathy in the 21st century: development of an empathy index rooted in social cognitive neuroscience and social justice. Soc Work Res 35(2):83-93

Gordon M (2005) Roots of Empathy. Changing the world child by child. Thomas Allen Publishers, Toronto

Groom V, Bailenson JN, Nass C (2009) The influence of racial embodiment on racial bias in immersive virtual environments. Soc Influ 4(3):1-18

Hagendoorn I (2004) Some speculative hypotheses about the nature and perception of dance and choreography. J Conscious Stud 11(3-4):79-110

Håkansson J (2003) Exploring the phenomenon of empathy. Doctoral dissertation, Stockholm University, Department of Psychology

Hamilton AF, Brindley RM, Frith U (2007) Imitation and action understanding in autistic spectrum disorders: how valid is the hypothesis of a deficit in the mirror neuron system? Neuropsychologia 45(8):1859-1868

Hasson U, Ghazanfar AA, Galantucci B, Garrod S, Keysers Ch (2012) Brain-to-brain coupling: a mechanism for creating and sharing a social world. Trends Cogn Sci 16(2):114-121

Hoffman ML (1987) The contribution of empathy to justice and moral judgment. In: Eisenberg N, Strayer $\mathrm{J}$ (eds) Empathy and its development (Cambridge studies in social and emotional development). Cambridge University Press, Cambridge, pp 47-80

Hoffman ML (2001) Empathy and moral development: implications for caring and justice. Cambridge University Press, New York

Iacoboni M (2009) Mirroring people; the science of empathy and how we connect with others. Picador, New York

Iacoboni M, Dapretto M (2006) The mirror neuron system and the consequences of its dysfunction. Nat Rev Neurosci 7(12):942-951

Ickes W (1997) Empathic accuracy. Guilford Press, New York

Ioannidou F, Konstantikaki V (2008) Empathy and emotional intelligence: what is it really about? Int J Caring Sci 1(3):118-123

James R, Blair R (2007) Empathic dysfunction in psychopathic individuals. Farrow TFD, Woodruff PWR (eds) Empathy in mental illness. Cambridge University Press, New York, pp 3-16

Kaukiainen A, Björkqvist K, Lagerspetz K, Österman K, Salmivalli C, Rothberg S, Ahlbom A (1999) The relationships between social intelligence, empathy, and three types of aggression. Aggress Behav 25(2):81-89

Keysers Ch (2011) The empathy brain. CreateSpace, Seattle

Keyserss Ch, Gazzola V (2010) Social neuroscience: mirror neurons recorded in humans. Curr Biol 20(8):353-354

Kirk U (2012) The modularity of aesthetic processing and perception in the human brain: functional neuroimaging studies of neuroaesthetics. In: Shimamura AP, Palmer SE (eds) Aesthetic science: connecting minds, brains, and experience. Oxford University Press, New York, pp 318-336

Lawrence EJ, Shaw P, Baker D, Baron-Cohen S, David AS (2004) Measuring empathy: reliability and validity of the empathy quotient. Psychol Med 34(5):911-924

Lee N, Broderick AJ, Chamberlain L (2006) What is neuromarketing? A discussion and agenda for future research. Int J Psychophysiol 63:199-204

Lietz CA, Gerdes KE, Sun F, Geiger JM, Wagaman A, Segal EA (2011) The Empathy Assessment Index (EAI): a confirmatory factor analysis of a multidimensional model of empathy. J Soc Soc Work Res 2(2):104-124

Lin M-Ch (2011) Predicting dyadic synchrony in early childhood: maternal, child, and contextual antecedents. Auburn University, Alabama. https://etd.auburn.edu/bitstream/handle/10415/2468/ Lin\%20Dissertation\%202010-12-10.pdf?sequence=2. Accessed 26 Nov 2014

Lorenz T, Vlaskamp BNS, Kasparbauer A-M, Mörtl A, Hirche S (2014) Dyadic movement synchronization while performing incongruent trajectories requires mutual adaptation. Front Hum Neurosci 8:461

Lusty M (2011) Synchronized dance therapy for autism. Cobbers on the brain. http://cobbersonthebrain. areavoices.com/2011/12/10/synchronized-dance-therapy-for-autism/. Accessed 26 Nov 2014

Mead GH (1967) Mind, self, and society: from the standpoint of a social behaviorist. University of Chicago Press, Chicago 
Meltzoff AN (2011) Social cognition and the origins of imitation, empathy, and theory of mind. In: Goswami U (ed) Blackwell handbook of childhood cognitive development. Blackwell, Oxford, pp 49-75

Mukamel R, Ekstrom AD, Kaplan J, Iacoboni M, Fried I (2010) Single-neuron responses in humans during execution and observation of actions. Curr Biol 20(8):750-756

Oberman LM, Ramachandran VS (2007) The simulating social mind: mirror neuron system and simulation in the social and communicative deficits of autism spectrum disorder. Psychol Bull 133(2):310-327

Oberman LM, Hubbard EM, McCleery JP, Altschuler EL, Ramachandran VS, Pineda JA (2005) EEG evidence for mirror neuron dysfunction in autism spectrum disorders. Cogn Brain Res 24(2):190-198

O'Connor LE, Jack BW, Lewis T, Mulherin K, Crisostomo PS (2007) Empathy and depression: the moral system on overdrive. In: Farrow TFD, Woodruff PWR (eds) Empathy in mental illness. Cambridge University Press, New York, pp 49-75

Pavlovich K, Krahnke K (2012) Empathy, connectedness and organisation. J Bus Ethics 105(1):131-137

Pearlman K (2009) Cutting rhythms: shaping the film edit. Focal Press, Burlington

Peck TC, Seinfeld S, Aglioti SM, Slater M (2013) Putting yourself in the skin of a black avatar reduces implicit racial bias. Conscious Cogn 22(3):779-787

Piaget J (2008) The moral judgment of the child. Free Press Paperbacks, New York

Pikovsky A, Rosenblum M, Kurths J (2003) Synchronization: a universal concept in nonlinear sciences. Cambridge University Press, New York

Praszkier R, Nowak A (2012) Social entrepreneurship: theory and practice. Cambridge University Press, New York

Ramachandran VS (2000) mirror neurons and imitation learning as the driving force behind "the great leap forward" in human evolution". Edge, 69. http://www.edge.org/3rd_culture/ramachandran/ ramachandran_p1.html. Accessed 26 Nov 2014

Ramachandran VS (2006) Mirror neurons and the brain in the vat. http://www.edge.org/3rd_culture/ ramachandran06/ramachandran06_index.html. Accessed 26 Nov 2014

Ramachandran VS, Oberman LM (2006) Broken mirrors: a theory of autism. Sci Am 63:69

Ramseyer F, Tschacher W (2008) Synchrony in dyadic psychotherapy sessions. In: Vrobel S, Rossler OE, Marks-Tarlow T (eds) Simultaneity: temporal structures and observer perspectives. World Scientific, New Jersey, pp 329-347

Rizzolatti G, Fabbri-Destro M (2008) The mirror system and its role in social cognition. Curr Opin Neurobiol 18(2):179-184

Rizzolatti G, Fabbri-Destro M (2010) Mirror neurons: from discovery to autism. Exp Brain Res 200(3-4):223-237

Rizzolatti G, Fogassi L (2014) The mirror mechanism: recent findings and perspectives. Philos T R Soc B. doi:10.1098/rstb.2013.0420

Rogers CR (2003) Client-centered therapy: its current practice, implications, and theory. Robinson Publishing, London

Roy S (2010) The psychology of empathy. Futurehealth. www.futurehealth.org/populum/page.php?f= The-Psychology-of-Empathy-by-Saberi-Roy-100620-281.html. Accessed 26 Nov 2014

Sacrey L-AR, Germani T, Bryson SE, Zwaigenbaum L (2014) Reaching and grasping in autism spectrum disorder: A review of recent literature. Front Neurol 5:6. http://www.ncbi.nlm.nih.gov/pmc/articles/ PMC3899541/. Accessed 26 Nov 2014

Schiepek G (2009) Complexity and nonlinear dynamics in psychotherapy. Eur Rev 17(2):331-356. doi:10.1017/S1062798709000763

Segal EA (2007) Social empathy: a tool to address the contradiction of working but still poor. Fam Soc 88(3):333-337

Segal EA (2011) Social empathy: a model built on empathy, contextual understanding, and social responsibility that promotes social justice. J Soc Serv Res 37(3):266-277

Segal EA, Wagaman MA, Gerdes KE (2012) Developing the Social Empathy Index: an exploratory factor analysis. Adv Soc Work 13(3):541-560

Shimamura AP (2013a) Psychocinematics: issues and directions. In: Shimamura AP (ed) Psychocinematics: the aesthetic science of movies. Oxford University Press, New York, pp 1-8

Shimamura AP (2013b) Presenting and analyzing movie stimuli for psychocinematic research. Tutor Quant Methods Psychol 9(1):1-5 
Society for Neuroscience (2008) Mirror neurons. Washington, DC: Society for neuroscience, November 2008. https://docs.google.com/document/d/1B3GvHFOzSFiOo69dt9ngqNs0Ap471WwPbvNrVejw Hv8/edit?hl=en_US. Accessed 26 Nov 2014

Staemmler FM (2011) Empathy in psychotherapy: how therapists and clients understand each other. Springer, New York

Stephens GJ, Silbert LJ, Hasson U (2010) Speaker-listener neural coupling underlies successful communication. Proc Natl Acad Sci USA 107(32):14425-14430

Stern DN (2004) The present moment in psychotherapy and everyday life. W. W. Norton \& Company, New York

Stotland E (1969) Exploratory investigations of empathy. Adv Exp Soc Psychol 4:271-314

Tager-Flusberg H (2007) Evaluating the theory-of-mind hypothesis of autism. Curr Dir Psychol Sci 16(6):311-315

Thompson E (2001) Empathy and consciousness. J Conscious Stud 8(5-7):1-32

Trevarthen C, Daniel S (2005) Disorganized rhythm and synchrony: early signs of autism and Rett syndrome. Brain Dev 27:S25-S34

Tschacher W, Scheier CH, Grawe K (1998) Order and Pattern Formation in Psychotherapy. Nonlinear Dyn Psychol Life Sci 2(3):195-215

Valdesolo P, DeSteno D (2011) Synchrony and the social tuning of compassion. Emotion 11(2):262-266

Williams JHG, Whiten A, Suddendorf T, Perrett DI (2001) Imitation, mirror neurons and autism. Neurosci Biobehav Rev 25(4):287-295

Wiltermuth SS, Heath C (2009) Synchrony and cooperation. Psychol Sci 20(1):1-5 